\title{
RESPONSABILIDADE SOCIAL COMO AÇÃO CIDADÃ? DESMASCARANDO A PRÁTICA DISCURSIVA DE UMA NOVA EXIGÊNCIA DA ÉTICA DE MERCADO
}

\section{SOCIAL RESPONSIBILITY AS CITIZEN ACTION? UNMASK THE DISCURSIVE PRACTICE OF A NEW REQUIREMENT OF THE ETHIC OF MARKET}

\author{
lael de Souza ${ }^{1}$ \\ Ryan Ribeiro de Azevedo ${ }^{2}$ \\ Cléverson Vasconcelos da Nóbrega ${ }^{3}$
}

\section{RESUMO}

O presente trabalho tem como objetivo propor a reflexão e apresentar algumas falácias e práticas discursivas que envolvem a ética empresarial, a responsabilidade social, o desenvolvimento sustentável e a valorização do sujeito trabalhador como rearranjos e renovações necessários às novas exigências da base técnico-material da produção capitalista flexibilizada. É feito um esforço pelos autores no sentido de tentar desmascarar tais estratégias, adotadas por algumas empresas, que aparentemente passam a atuar em prol da qualidade de vida e bem estar dos trabalhadores transformados em colaboradores, demonstrando as novas modalidades de extração do mais valor com 0 consentimento do trabalhador. Desinverter a realidade propositalmente invertida a fim de que o social retome o controle e gestão do social para o social, com o social e pelo social. Para isso se faz necessário uma reflexão que tenha por método a análise concreta de situações concretas, o que procuramos aqui realizar, pois a mudança de atitude começa pela mudança daquele que vê.

Palavras-chave: Responsabilidade social - Mercado - Trabalhador - Capitalismo.

\section{ABSTRACT}

The following paper aims to propose a reflection and present some fallacies and discursive practices which involve business ethics, social responsibility, sustainable development and the working class appreciation as rearrangements and necessary renewal to meet the latest demand for the technical-materialistic base of the flexible capitalist production. An effort is made by the authors in the sense of attempting to uncover such strategies, employed by some organizations, which apparently move toward workers' quality of life and welfare, turning workers into stakeholders, demonstrating the new modalities of surplus value extraction with worker consent. Unreversing reality purposely reversed in order to regain control of social management to social, with social and for social. To achieve it, a reflection whose method is the concrete analysis of concrete situations is mandatory, what is intended to be developed here, since posture modification starts by the transition of the one who notes it.

Keywords: Social responsibility - Market - Worker - Capitalism. 


\section{INTRODUÇÃO}

Nas últimas décadas, encontramos na literatura nacional e estrangeira uma discussão vasta acerca do tema Responsabilidade Social Empresarial (RSE) ou Responsabilidade Social Corporativa (RSC) - aqui tratadas como sinônimos -, em sua grande maioria, enaltecendo o papel das organizações como propulsoras da melhoria das condições de vida da sociedade. O que a princípio, poderia ser visto como mais um modismo, entre tantos outros existentes na área administrativa, começa a ganhar força e consolidar-se, encontrando empresas mais adeptas, principalmente pela necessidade de se destacar em relação aos concorrentes em um mercado hipercompetitivo.

Assim, a RSE parece ser um fenômeno sem volta, uma vez que se encontra incentivada pelo Estado, incapaz de assumir suas responsabilidades perante a sociedade, e cultuada pelas empresas, usando-a como uma estratégia de melhoria da sua imagem, atendendo as novas exigências dos clientes/consumidores, que passam a se diferenciar dos demais através do consumo eticamente correto, pelo qual paga-se um preço mais elevado.

Esse novo paradigma atitudinal-comportamental assumido pelas organizações contribui para que elas se projetem, perante a sociedade, como os novos protagonistas dos rumos e diretrizes da vida política, econômica, cultural, contrapondo a imagem de eficiência e sucesso ao de ineficiência, fracasso e desperdício dos Estados Nacionais, difundindo uma imagem de agente social consciente e preocupado em assumir "os riscos sociais e ambientais gerados pelas suas capacidades produtivas, e mais do que isso" (CATTANI E SALMON, 2009, p. 289), diferentemente da impotência demonstrada pelo Estado na resolução e enfrentamento dos problemas sociais e ambientais, mostram ser capazes mesmo de preveni-los.

Essa combinação de benefício social e vantagem competitiva, isto é, uma relação de ganha-ganha, consiste no discurso dominante e se baseia na premissa de evolução espontânea do gerenciamento, cuja intenção é o despertar para outras dimensões, como por exemplo, as extra-econômicas. Assim, a RSE é pautada, entre outros aspectos, na dita transparência dos negócios e no respeito ao direito, valores e interesses de todos aqueles que, direta ou indiretamente, são por ela afetados. 
No entanto, para uma reflexão mais aprofundada acerca da temática, é importante que levemos a discussão para um ângulo distinto e observemos a existência da outra face da moeda, das múltiplas determinações que compõem a totalidade das relações sociais e materiais da produção capitalista a fim de que compreendamos o que está obliterado pelas renovadas práticas culturais das organizações em sua ânsia pelo poder, pelo controle social e pela reprodução exponencial do mais-valor.

O contexto histórico-social atual do desenvolvimento do capital e das forças produtivas explica as razões do porque ser eticamente responsável, social e ambientalmente, é um bom negócio. Não podemos esquecer que num mundo onde o sentido da vida é o cálculo, todas as ações sociais são racionais e meticulosamente maquinadas para se atingir os objetivos almejados. Logo, há uma linha muito tênue, que pretensa e falsamente, separa o bem estar social dos interesses e necessidades de extração do mais valor.

Este ensaio tem como objetivo propor algumas reflexões sobre o temaproblema, tomando como ponto de partida o filme The Corporation, procurando apresentar o que pode estar oculto por trás do discurso organizacional, questionando se as ações praticadas podem, de fato, ser consideradas como socialmente responsáveis. Nas seções a seguir, contestamos a (pseudo) ética empresarial atrelada à prática da responsabilidade social pelas empresas e destacamos a incapacidade (ou seu novo papel e forma de atuação no rearranjo metabólico do sistema capitalista?) do Estado, enquanto promotor das políticas públicas, tornando-se agente e incentivador da filantropia empresarial. Por fim, levantamos alguns questionamentos sobre a atuação das empresas inseridas no paradigma da responsabilidade social.

\section{DESINVERTER O QUE FOI PROPOSITALMENTE INVERTIDO!}

Iniciamos nossa análise reflexiva a partir de uma sentença: enquanto a lógica preponderante for a lógica do capital e da manutenção e reprodução do sistema capitalista, nenhuma ação, seja de cunho sociocultural, socioeconômico ou sociopolítico, atenderá, de fato, às necessidades e interesses humanos, mas sim aos interesses e necessidades das relações mercantis e da sociabilidade de mercado. 
Porém, há muito tempo, como bem demonstram Lukacs (s/d), Marx/Engels (1982) e Tonet (1995), a burguesia construiu o conhecimento histórico de que a forma por excelência para exercer sua dominação político-econômica é a república democrática burguesa, ou seja, não a realização de uma democracia-social, e sim um regime em aparência similar, porém jamais em essência: a social democracia.

A ilusão de liberdade de escolha, quando todas elas são limitadas e delimitadas pela condição socioeconômica dos indivíduos sociais, permite influenciar os grupos sociais justamente na formação de seus valores éticos e morais, já que são os mass media, controlados pelos proprietários dos meios de produção, que formam as opiniões e fazem a cabeça dos indivíduos sociais.

Também não podemos esquecer que são o braço direito da dominação racional-legal exercida pelo Estado, sendo, dentre seus aparelhos ideológicos, conforme Althusser (s/d), um dos essenciais, com exceção da instituição escolareducacional, que é o aparelho ideológico de Estado por excelência, isto porque obriga a todos os cidadãos em idade escolar a frequentá-la, pois é nesse espaço-social que serão inculcados os princípios viabilizadores da dominação racional-legal: a razão, "o respeito pela ciência, pelos ideais e sentimentos que estão na base da moral democrática" (DURKHEIM, s/d, p. 62).

É assim que a sociabilidade de mercado normatiza sua regulação. As normas, regras e valores socioculturais traduzem as exigências e necessidades impostas ao funcionamento e reprodução das relações mercantis. As novidades em relação às ações empresariais e aos procedimentos e processos das grandes corporações encontram ressonância nas renovadas modificações dos consumidores, em especial dos pobres, que bem administrados, conforme Mészáros, conferem à sociedade um duplo benefício: "trabalhando e consumindo. [...] Pois é do interesse das nações ricas que a maior parte dos pobres quase nunca estejam ociosos, mas gastem continuamente o que ganham" (MÉSZÁROS, 1996, p. 52), dado que o processo produtivo engloba a relação de interdependência entre produção-consumo-distribuiçãocirculação, como elucida Teixeira (1995).

Do mesmo modo como Weber (1985) evidenciou que a ética protestante respondia a necessidade de justificação da produção do mais-valor, assim também a 
responsabilidade social é uma ação que procura mitigar a imagem das empresas e corporações como externalizadoras de custos, criando outra, de consciente, responsável e comprometida com o social e os ecossistemas. ${ }^{4}$

Não é outra a razão das inovações na gestão - gestão de pessoas ao invés de recursos humanos, por exemplo, como elucida Moura (2004), uma mudança conceitual que causa sensíveis modificações atitudinais-comportamentais por sentir-se reconhecido, valorizado enquanto gente, pessoa -, nos métodos e processos da organização do trabalho e da produção. A responsabilidade social corporativa é parte desse processo. Segundo o discurso oficial, mera prática discursiva que compõe a tática das estratégias montada pelo marketing social, a responsabilidade social corporativa compreende:

uma forma de conduzir os negócios da empresa de tal maneira que a torna
parceira e co-responsável pelo desenvolvimento social. A empresa socialmente
responsável é aquela que possui a capacidade de ouvir os interesses das
diferentes partes (acionistas, funcionários, prestadores de serviço,
fornecedores, consumidores, comunidade, governo e meio-ambiente) e
conseguir incorporá-los no planejamento de suas atividades, buscando atender
às demandas de todos e não apenas dos acionistas ou proprietários
(INSTITUTO ETHOS, 2002).

Assumir uma postura destoante desse canto de cisne parece despropositada e mesmo irracional. No entanto, quando conseguimos ir além do senso comum formado pelos que controlam a cabeça desse heterogêneo meio social, transcendendo a explicação e ascendendo à compreensão da totalidade das relações sociais e de produção que configuram os comportamentos, as ações, os pensamentos, as sensações e sentimentos contraditórios, processuais, conflituosos, dialéticos da sociabilidade humana, constatamos que o comportamento desviante do legitimado socialmente, reporta a um posicionamento e leitura de mundo feita criticamente, embasada filosófica-cientificamente e contextualizada histórica, econômica, política, psicológica e antropologicamente.

É assim que ousamos desmontar o padrão sociocultural aceito e legitimado socialmente. Como afirma a Dr. ${ }^{\text {a }}$ Elaine Bernard, diretora executiva do programa sobre sindicato da Universidade de Harvard, no documentário The Corporation: 
Responsabilidade social não é uma mudança profunda porque é uma tática voluntária. Uma tática, uma reação a um certo mercado, a essa altura. Se a corporação interpretar o mercado de outro modo, ela mudará. Num dia é Bambi; no outro, Godzila.

Milton Friedman, uma referência na área econômica, também complementa a análise sobre o assunto na sequência do documentário, dizendo o seguinte:

Como se define socialmente responsável? Não é função da corporação decidir o que é socialmente responsável. Não é especialidade dela, não é o que os acionistas pedem a ela. Elas estão ultrapassando um limite, e isso não é democrático.

Num outro momento do documentário, Friedman assevera, a respeito da mesma problemática:

Um prédio pode ter opiniões morais? Ter responsabilidade social? Se ele não pode, o que significa dizer que uma corporação pode? Uma corporação é simplesmente uma estrutura legal artificial, mas seus membros, os acionistas, os executivos, os funcionários, todos eles têm responsabilidades morais.

Para fechar essa sequência de falas selecionadas e sistematizadas por nós acerca do documentário The Corporation, contextualizando e reiterando as reflexões que aqui desdobramos sobre a temática em questão, transcrevemos o comentário de Noam Chomsky, consecutiva a de Friedman, exposta acima:

É correto assumir que todo ser humano, de carne e osso, não corporações, mas todo ser humano, é uma pessoa moral. Temos os mesmos genes, somos mais ou menos iguais, mas nossa natureza, a dos humanos, permite todos os tipos de comportamentos. Todos, sob algumas circunstâncias, poderiam ser um assassino condenado à morte ou um santo. (...) Ao olhar uma corporação, como ao olhar um dono de escravos, você quer diferenciar a instituição do indivíduo. Escravidão e outras formas de tiranias são monstruosas, mas os participantes delas podem ser pessoas muito boas. Benevolentes, cordiais, carinhosas com os filhos, até com os escravos, importando-se com as pessoas. Como indivíduos, podem ser qualquer coisa. Em seu papel institucional, são monstros porque a instituição é monstruosa. O mesmo é verdade aqui.

O que todas essas falas demonstram ao se contraporem e complementarem dialeticamente, representando a lógica contraditória do metabolismo sistêmico do capital e da sociabilidade capitalista? Denotam a operacionalidade e funcionalidade da lógica de mercado, da subsunção dos valores de uso aos valores de troca, de como as corporações necessitam maquiar seus verdadeiros interesses e intenções para garantir 
a reprodução do mais-valor, pois elas, enquanto instituições, são coisas, não têm sentimentos, nem preocupações relacionadas ao bem comum, a res-pública, visando, tão somente, conforme explicita Napoleoni (1981), garantir as condições para a ampliação exponencial da mais-valia absoluta e relativa. A diferença é que os meios para atingir o fim supremo - a valorização do valor - foram recobertos por envoltórios de consciência ambiental, trabalhista, social, atendendo as novas exigências do consumo eticamente correto.

Aqueles que personificam os interesses e necessidades do capital e de seus órgãos tornam-se agentes do sistema, da Matrix, que é a sociabilidade capitalista, defendem-no e protegem-no de todas as ameaças e riscos, alimentando as ilusões ideoculturais por ele produzidas a todo e qualquer custo, fazendo com que os indivíduos sociais acreditem ser as sombras a realidade, manipulando-os sutilmente para a manutenção de seus propósitos. Essas personas, enquanto personificação do capital, são a-morais e anti-éticas, porque atuam não como pessoas, mas sim como instrumentais de um instrumento que as possui e usufrui a seu bel prazer.

A dita RSE, trata-se, outrossim, dentro desse contexto, de uma nova prática exigida pelas mudanças do mercado consumidor, aliviando o sentimento de culpa dos consumidores com consciência ecológica, com consciência social (contra o trabalho infantil, contra o trabalho escravo, contra a inanição e miséria etc.) e demais consciências produzidas através do marketing social.

Portanto, acreditamos que a primeira e imprescindível atividade para desmascarar e desmontar essa prática discursiva das novas exigências éticas do consumo mercantil, é buscar compreender os arranjos e rearranjos das relações de força e poder entre as classes sociais para a garantia da continuidade da hegemonia de uma delas e do modo de vida que personificam, protegem e defendem. Compreendendo, passamos ao segundo momento, que é propagar essa compreensão, esse conhecimento para o social, utilizando dos meios alternativos contra-hegemônicos a fim de que instrumentalizemos os grupos e indivíduos sociais com o conhecimento filosófico-científico essencial e fundamental para a luta por sua emancipação. 


\section{DAS SOMBRAS À REALIDADE: PARA ALÉM DA PSEUDOCONCRETICIDADE}

Como já asseverava Weber (1985), o mundo moderno é marcado pelo processo de racionalização. Toda ação social é uma ação social racional, isto é, os indivíduos sociais ao agirem levam em consideração os outros e, acima de tudo, as formas de ação socialmente aceitas e legitimadas, de modo que as expectativas sejam atendidas para a mais precisa adequação entre meios e fins, pois que o sentido da vida, na sociabilidade capitalista, é o cálculo, daí a regulamentação das ações e interações sociais pelo direito racional-legal, tipo de dominação por excelência do sistema metabólico do capital, regulamentada pela burocratização do social.

Num mundo assim, extremamente calculista, individualista, hedonista e imediatista, pautado nos interesses egoísticos dos valores de troca, a única coisa que importa é ter, mantendo as aparências, dado que a lógica imperante delas se nutre. Cada vez mais, os indivíduos sociais tornam-se superficiais, suas relações, artificiais e artificializadas, e assim prosseguem, cativos, no entanto, dóceis, obedientes, subservientes e mesmo pró-ativos em tornar suas prisões confortáveis, dando sugestões para aprimorar as maneiras de controle do trabalho pelo capital, complementando e consubstancializando o processo de subsunção real daquele por esse.

Entretanto, as táticas do capital - e da sociabilidade fetichizada do mercado -, sempre renovadas, são tão sedutoras, tão envolventes, que a entrega se dá de coração, mente, corpo e mesmo alma. É assim que conseguimos compreender as novas práticas organizacionais das corporações para garantir a efetiva subsunção do trabalho pelo capital, de modo que aquele não imponha resistências, mas se integre aos novos processos e procedimentos da produção e do trabalho de bom grado, como partícipe e colaborador, dando mesmo sugestões de como devem ser implementadas as renovações na base técnico material da produção flexibilizada.

A análise crítico-reflexiva das razões da passagem do fordismo-taylorismo para a produção e processos toyotizados, auxilia-nos a compreender como alguns dos efeitos colaterais da produção standartizada e da organização racional científica 
taylorizada dos processos da produção e do trabalho foram rearranjados pela incorporação das práticas toyotistas, como exposto por Giovanni Alves (2001).

É dentro desse contexto que também se insere a dita responsabilidade social corporativa, assentada em três pilares fundamentais, quais sejam: a) a ética empresarial, b) a preservação dos recursos naturais e c) o respeito aos trabalhadores. A crise do bem-estar social; a necessidade da reestruturação produtiva do capital para garantir fôlego à reprodução exponencial do mais-valor; a implantação da políticaeconômica neoliberal, criando e preparando a infraestrutura desse rearranjo estrutural global do capital e do seu sistema metabólico, são partes dos fatores que explicam e justificam as novas e renovadas práticas organizacionais e as mudanças em sua cultura.

Iniciaremos através da exposição do contexto que justifica esse aparente respeito aos trabalhadores. Um dos vários problemas causados pela organização da produção e trabalho fordista-taylorista decorre do fato de que o ser humano era comparado a uma máquina, racionalmente calculado como razão e mão, lubrificadas pelo incentivo econômico, garantidor da produtividade e do ritmo acelerado da produção.

Porém, o grande e grave problema, um dos vários que envolve os efeitos colaterais do fordismo-taylorismo, estava na questão de que os trabalhadores eram indiferentes ao seu trabalho, não se envolviam com o que faziam devido à parcelarização, à rotina maçante, massacrante e massificante, sendo que enquanto as mãos faziam sempre os mesmos movimentos sem requerer mais desse indivíduo do que mera mecanicidade, repetição, numa igualdade de tempos e movimentos decorados e viciados, a cabeça estava liberta para outras incursões, fazendo com que pensassem sobre sua própria condição de vida e trabalho, como foi apontado por Gramsci (1978), gerando, ao contrário do esperado, uma certa politização dos trabalhadores, resultando em sua efetiva organização e mobilização, tensionando as relações de força e poder entre capital e trabalho.

Como frear e reduzir à insignificância a resistência dos trabalhadores à exploração de sua força de trabalho, deixando de ser uma ameaça ao sistema? A concorrência intercapitalista, que exige a renovação constante das forças produtivas, 
revolucionando a base técnico-científica e material da produção, proporciona os contributos da nova fase capitalista, beneficiando o controle do trabalho pelo capital ao absorver o trabalhador não apenas racional, mas também, e acima de tudo, valorativa, sentimental e afetivamente. Reconhecimento, comunicação, pró-atividade, equipes, metas... mecanismos exigidos pela base técnico-material da produção e pelas experiências dos embates travados nas relações de poder e força entre capital e trabalho, arranjando-as e rearranjando-as conforme a maior ou menor organização e mobilização de uma ou outra classe.

Fica evidenciado, assim, que o respeito ao trabalhador é mera falácia, o que se pretende, de fato, é criar meios para garantir seu envolvimento global à produção e aos processos de trabalho, eliminando toda e qualquer forma de resistência. $O$ desemprego estrutural é um fator tático importantíssimo para esse aparente controle quase que absoluto do trabalho pelo capital.

O que dizer então da ética empresarial?! Sabemos que, dentro da lógica capitalista, a única ética é a ética de mercado, portanto, uma antiética, já que nas relações mercantis os homens são coisas e suas relações coisificadas e coisas não têm sentimentos, não valoram, apenas produzem mais valor. Os indivíduos sociais são suporte para a atividade realizada pelas coisas, daí o fetiche da mercadoria. A ética de mercado é estabelecida mediante uma necessidade imposta pela ética do consumo que, por sua vez, é estabelecida pela ética antiética da produção capitalista.

Atualmente, o que mais ouvimos falar é sobre ética no trabalho, ética e educação, ética empresarial, sendo a ética aplicada a todos os saberes e fazeres humanos. Qual a razão, ou razões, desse boom da e sobre a ética? Talvez, uma delas possa ser identificada através da lógica do desenvolvimento desigual e combinado do capital, que ao elevar o individualismo, o egoísmo, o hedonismo, a competitividade e concorrência para além dos limites racionalmente aceitáveis coloca em xeque a própria condição de reprodução da vida societal.

O capital e o sistema capitalista movimentam-se por contradição, de modo que é necessário pensar não a contradição, mas sim por contradição. Nesse caso, deveríamos nos questionar: qual ética pode haver numa produção que se funda e se retroalimenta de uma destruição contínua, planejada para o imediatismo do 
consumismo inconseqüente que dissipa as potencialidades da humanidade acumuladas no decurso da história? Não é por outra razão que Mészáros (1996) afirma que a produção, dentro da formação econômico-social capitalista, é uma produção destrutiva. Assim, desmonta-se o discurso falacioso do dito desenvolvimento sustentável.

É necessário decifrar o enigma da esfinge para não ser devorado por ela. Novos conceitos? Novas práticas? Novos processos? Novos procedimentos? Qual a novidade, afinal? Nada de novo; na verdade, renovadas maneiras de explorar o trabalhador, sua força de trabalho e extrair mais e mais valor.

\section{A PRÁTICA DISCURSIVA DA RESPONSABILIDADE SOCIAL COMO JOGADA DE MESTRE E FÔLEGO DO CAPITAL - A DESRESPONSABILIZAÇÃO DO ESTADO}

A filantropia empresarial é parte das ações que compõem a atuação da responsabilidade social corporativa. Podemos entender a tática da responsabilidade social como estratégia de proteção contra a precariedade crescente e avassaladora das condições de vida e trabalho do todo social, agravadas e aprofundadas pela políticaeconômica neoliberal.

Dentre as análises sociológicas, comungamos com aquelas que relacionam as mudanças de questão do e intervenção no social ao aumento massivo dos desempregados, expurgados da esfera produtiva. O discurso anteriormente utilizado de incapacidade pessoal e desajuste não se sustenta frente às alterações do mercado e mundo do trabalho. Esses espúrios são uma ameaça expressiva para a ordem social. Assim, esse cenário propicia a efervescência à filantropia empresarial antes que a situação fique fora de controle.

Filantropia, assistência ou caridade trabalham com a noção de benefício, de modo genérico, quando, na realidade, trata-se dos direitos à vida e ninguém tem que agradecer ou ficar devendo favores a quem quer que seja - Estado, empresas, instituições sem fins lucrativos - por isso. Porém, há instituições e empresas que usam e abusam do conceito de cidadania, enfatizando os direitos civis, mas secundarizando os políticos e econômico-culturais, deixando de lado, propositalmente, que a efetivação dos direitos à vida depende de condicionantes de ordem política e econômica. Como 
elucidam Moraes (2000), Wanderley (2000) e Rosemberg (2000), no âmbito dos supostos direitos sociais concorrem agentes que não têm o mandato para assegurar tais direitos.

O Estado é visto como ineficiente e incapaz de gerir a coisa pública e atingir os resultados e eficiência tão esperados. A sociedade civil é bem intencionada, tem boa vontade, mas falta a competência e os recursos. A solução é atribuir a execução desse script, desse papel, ao ator empresário/empresa/empreendedor social, ou seja, aquele que tem competência técnica para gerir problemas. Com base na concepção de cidadania, reclamam a denominação de instituições privadas com interesses públicos.

As ONG's, na década de 80, também acabaram desempenhando importante papel para evitar a explosão política-social, atuando como descompressoras altamente produtivas. A década de 80 assistiu ao processo de mobilização e organização política-social da sociedade civil, fazendo pressão para a reorientação das políticas sociais, públicas, estatais.

Contudo, a diversificação de atividades e crescente aumento do número de ONG's e a falta de uma legislação específica acabaram desvirtuando muito da proposta e trabalho original. Hoje as ONG's trabalham em sistema de parceria com instituições, municípios e estados, até como forma de dar continuidade a suas atividades, essenciais a um público em expansão geométrica, o que coloca em pauta 0 questionamento do seu potencial como partícipe da gestão/execução de políticas públicas, embora aponte o perigo da desresponsabilização do Estado como garantidor dessas mesmas políticas.

A filantropia empresarial é entendida pelos seus integrantes como uma das organizações do chamado terceiro setor. Os setores da economia, muito conhecidos por nós, porque estudados no ensino fundamental I e I| e ensino médio, são: a) primário, b) secundário e c) terciário. Mas, quais seriam os setores do social? Conforme os estudiosos, o primeiro seria o Estado, o segundo as Empresas e o terceiro as ONG's e instituições sem fins lucrativos, ou seja, entenda-se privado com fins públicos, portadoras de virtudes alheias ao Estado e ao mercado.

Essas instituições, organizações, empresas filantrópicas podem e fazem um sistema de parceria, mas o interessante é que ele se efetua sob a lógica de mercado e 
não do social, isto porque não há necessariamente uma construção comum de proposta ou projetos sobre o social, de modo que cada qual tira as vantagens e benefícios próprios da parceria.

Sobre a atuação das empresas com responsabilidade social, é interessante ressaltar um dos seus objetivos, que é complementar a ação do Estado (ineficaz, ineficiente, mau-gestor e mau-empreendedor), e o mais fundamental: numa relação de parceria e controle direto dos programas sociais, controle e influência que os grupos interessados/assistidos não têm. O Estado deixa de ser o promotor das políticas públicas e vira agente.

Vemos aqui um hibridismo entre o mundo do mercado e o mundo da política, como afirma Moraes (2000), com a transposição dos métodos que orientam o mercado

para o âmbito social: relação otimizada entre investimento e resultado. É aqui que entra a gestão pública tecnocrática, visando potencializar a eficiência do e no campo social, que é tratado como fórmula matemática, tecnicamente, com um fluxo previsível de ações controladas, como se o SOCIAL fosse um objeto - ou organismo, como entendem e tratam os funcionalistas - de intervenção rígido, isolado ou neutralizável.

\section{UM NOVO PARADIGMA PARA FAZER FRENTE ÀS NECESSIDADES DAS RELAÇÕES MERCANTIS}

A atuação das empresas dentro do paradigma da responsabilidade social traz um leque de questões a serem consideradas. Pontuemos algumas delas, as que, segundo nosso entendimento, são mais relevantes a nossa discussão.

Iniciemos pela incompatibilidade entre negócio e altruísmo. Decidir o que é de interesse público é tarefa das empresas, do mercado ou do Estado? Na verdade, essa é uma tarefa da política, e não do mercado. Não cabe à empresa identificar o que constitui interesse social, definir prioridades e resolver qual o montante de recursos a ser aplicado nesse ou naquele setor, considerando, sobretudo, que suas ações são orientadas pela lógica da otimização e do interesse econômico.

A campanha pela responsabilidade social também pode ser entendida como marketing empresarial, procurando atenuar a visão do mercado como o mundo do auto- 
interesse, funcionando como um mascaramento necessário à exigência do próprio mercado, uma vez que os consumidores tornam-se mais exigentes em relação as suas necessidades e produtos consumidos, segundo a teoria da hierarquia das necessidades, de Maslow. Aliada a ela, temos a teoria de Fred Hirsch, que afirma que os indivíduos se diferenciam socialmente através da produção de necessidades num sistema em que "mais riqueza do tipo alcançável por todos significa, paradoxalmente, maior disputa pelo tipo de riqueza só alcançável por alguns" (GARCIA, 2004, p. 47).

É assim que o marketing empresarial ganha fôlego e se propaga como epidemia através do marketing social. As marcas são fortalecidas não pelos produtos, mas por meio de valores a elas agregados, que lhes confere certa reputação, pois os consumidores ao adquirirem a marca se apropriam - ou melhor, têm a impressão de se apropriar e adquirir - os atributos da marca, é a idéia de bens posicionais, de Hirsch, o produto, ou melhor, a reputação do produto é a sua imagem e reputação reflexiva ${ }^{5}$

Há uma gama de interesses que se mesclam e imiscuem obliterando uma visão mais totalizadora das mediações e conexões entre as relações sociais e de produção produtoras dessa nova configuração do real. Não podemos negar que essas parcerias, apesar dos vieses e enviesamentos, acabam contribuindo para captar recursos para a realização dos projetos sociais. Mas como podemos acompanhar a aplicação desses recursos e influenciar no seu controle e processo decisório?

Para a segunda questão, não há resposta, mas para a primeira há uma tentativa, implementada pelo Ibase (Instituto Brasileiro de Análises Sociais e Econômicas), organização não-governamental fundado por Betinho, que inaugurou a campanha para a produção do balanço social pelas empresas, cujo critério norteador é a transparência e controle social para - e não pelo - social. O Instituto procurou instrumentalizar as empresas para isso, entregando-Ihes um formulário e incentivando tornando vantajosa a participação, pois as empresas operam sob o social através da lógica empresarial - a aderência à campanha pela entrega de um selo que funcionou como uma espécie de distintivo (marketing social) para caracterizar o empenho e a responsabilidade social empresarial.

Apesar da intenção e iniciativa da organização não-governamental de Betinho, é preciso lembrar que o processo de prestação de contas de uma empresa 
privada não se dá a partir dos mesmos mecanismos de participação de uma empresa que movimenta recursos públicos.

É interessante observar que as empresas fazem a filantropia, atuam com responsabilidade social caso isso reverta em vantagem, funcionando como o sistema de mercado: por interesse privado na troca, que aparece e aparenta reverter para o bem público, ao menos no caso em questão. O privado com fins públicos acaba contribuindo para o upgrade da imagem da empresa, para a fidelidade dos consumidores em relação aos seus produtos e uma maior margem de lucros.

Não é por outra razão que a campanha pela responsabilidade social das empresas no Brasil, em meados da década de 80, mais precisamente 1982, é coroada com premiações. Dentre elas está o prêmio $\mathrm{ECO}$, patrocinado e criado pela Câmera Americana de Comércio de São Paulo, a segunda maior do mundo. As Câmaras Americanas de Comércio representam uma forma de associação empresarial com o objetivo de estreitar relações políticas e econômicas entre os Estados Unidos e os demais países.

"O ECO é um tipo peculiar de competição em que simplesmente a participação no processo é vantajosa, já que permite que as empresas divulguem seus programas e, consequentemente, sua marca" (GARCIA, 2004, p. 35). Nessas premiações o processo avaliativo pauta-se no sistema de classificação de qualidade adotado pela empresa, ou seja, as ações sociais e o social é enrijecido pela formatação dos métodos, técnicas e processos organizacionais de eficiência e eficácia, medidas em termos estatísticos e numéricos das vantagens e resultados obtidos segundo critérios da gestão empresarial para o interesse social/público, e o público, o social não têm nenhum poder de interferência, decisão e controle sobre os resultados obtidos, resultados que nem sempre atendem as verdadeiras necessidades desse social.

Como exemplo, poderíamos utilizar a cena do filme Quanto Vale ou é Por Quilo? onde uma empresa sem fins lucrativos compra computadores e doa a uma comunidade carente para inseri-la na era digital e da internet, mas os computadores estão sucateados, não são novos e foram super-faturados, garantindo um negócio vantajoso com o social para o privado com fins públicos. 
O ECO foi uma tática que deu muito certo, dando corpo à idéia e prática da cidadania empresarial, constituindo o terceiro setor das empresas com responsabilidade social, tornando públicas as iniciativas em curso, angariando recursos do Estado publicização do privado -, criando uma fábrica de ações sociais, formatando as exigências para um processo de competição, associando a competência do mercado ao engajamento político da sociedade civil.

Mas será que existe nesse meio empresarial grupos de fato que acreditam ser possível humanizar o mercado e o capitalismo, retomando, de forma recontextualizada, as utopias humanistas dos socialistas crítico-utópicos e mesmo da ala progressista da Igreja Católica?

Segundo consta, o pensamento crítico das bases empresariais estaria representado na formação de um grupo que se constituiu em 1987 em oposição à FIESP (Federação das Indústrias do Estado de São Paulo), denominado PNBE (Pensamento Nacional das Bases Empresariais). Havia insatisfação política em relação à FIESP como representante da classe.

O PNBE assumiu postura extremamente ativa na economia, que se traduziu não somente no acompanhamento crítico das medidas que o governo implementava, mas também na apresentação de propostas construídas a partir de estudos feitos em outros países que encontraram saídas bem sucedidas para períodos de crise econômica. Além dessa participação como ator econômico interessado, o PNBE institucionalizou a idéia do engajamento cívico no meio empresarial. Os mundos da produção e da política se fundiram num discurso que se pretendia novo e progressista. Uma das manifestações dessa síntese foi a POLITIZAÇÃO de temas de interesse social, definidos como pauta prioritária da atenção empresarial (GARCIA, 2004, p. 38).

Parece que o empresariado procurou reverter o quadro da década de 80 , caracterizada pelo segmento dos proprietários dos bens e meios de produção como década perdida, perdida porque foi o momento da conquista dos espaços sociais pelos movimentos sociais organizados pelo seu processo de politização e conscientização social. Os empresários teriam de reaver o público para os interesses privados, privatizando o público a partir do momento que passam a patrocinar as ações sociais e controlar os recursos e programas fazendo a administração gerencial do público, cabendo ao Estado apenas gerenciar e não promover as políticas sociais, públicas, estatais. 
Os iniciadores desse combate ao Estado de Bem-Estar foram os norteamericanos, que em 1953, sob influência do livro de Howard Bowen - Responsabilities of the Businessman, incitaram as empresas à filantropia empresarial e à responsabilidade social, trazendo para a ação social referências de eficácia e eficiência não reconhecidas pela histórica atuação do Estado como o articulador oficial dessa esfera.

Além do PNBE, outro grupo que teve grande influência para a difusão da responsabilidade social das empresas é o GIFE (Grupo de Institutos, Federações e Empresas), consolidado em 1995, associando e agregando organizações empresariais que se destacaram por razões de natureza ética.

Iniciativas até então isoladas, sem parâmetros comparativos e sem estratégias eficazes de divulgação de resultados sofreram mudanças com a criação de uma entidade representativa, cujo propósito era aperfeiçoar e difundir os conceitos e práticas relacionados à responsabilidade social das empresas. A partir da constituição do GIFE, houve maior incremento das iniciativas empresariais no âmbito social, assim como uma certa influência no formato e gestão dos programas sociais. ${ }^{6}$ Sem dúvida, para o que antes se caracterizava como um movimento, o GIFE representou um nível de maior institucionalização e qualificação. Ser associado a esse grupo passou a representar uma condição mais bem definida no campo da responsabilidade corporativa. (GARCIA, 2004, p. 39)

Não menos importante, talvez de importância crucial, é o Instituto Ethos de Empresas e Responsabilidade Social, fundado em 1999, responsável pelas atividades de natureza mobilizatória, portanto, pela propaganda e divulgação das idéias e ações sociais, tanto para o campo empresarial quanto para os leigos, leitores e espectadores dos veículos de propaganda.

Procura fundir a política ao mercado, apresentando o empresário como um ator político responsável e seus agentes promotores são recrutados não mais na área das ciências humanas e sim no âmbito da administração, comunicação social e marketing, cujo princípio e fim é a gestão de resultados, caracterizada pela preocupação com o retorno do investimento, pela utilização de padrões de planejamento e avaliação próprios do mundo empresarial e, finalmente, pelo marketing das ações e de seu desempenho. 
Vemos, portanto, que o social não é só um negócio, mas um negócio dos melhores, negociado e negociável por todos os setores do social, pois até o Estado aproveita para fazer a terceirização dos serviços, onde o social se torna sócio e detêm as ações majoritárias, não dos lucros, mas dos dividendos, porque sua função, quase que exclusiva, é pagar as contas.

\section{CONSIDERAÇÕES FINAIS}

O modo de vida capitalista, pautado na coisificação das relações humanas, então desumanizadas e reificadas, aperfeiçoa cada vez mais suas formas de controle sobre o social a fim de garantir a hegemonia e poder do capital, fortalecida pela produção de renovados conceitos, renovados valores, revestidos de falsa ética e falsa moral.

A cada nova crise, o capital procura se reestruturar como forma de tomar fôlego para dar continuidade a seu processo fagocitoso de produção destrutiva, e na correlação de forças dos embates entre ele e seu contrário - que dialeticamente o nutre e mantém, reproduzindo-o -, o trabalho, vai adquirindo novos aliados, novos agentes, num sistema de alianças, parcerias e colaborações que faz de seus parceiros suas novas personas.

Assim acontece com os Estados Nacionais, cuja aparente imagem de insuficiência, incompetência, ineficiência, incapacidade de gerir a coisa pública possibilita, porque justifica e convence, a transferência do público para o privado, permitindo que o privado se aproprie, indevidamente, do capital social arrecadado pela coisa pública e o utilize para interesses exclusivamente capitalistas.

Enganam-se aqueles que acreditam no mito do Estado mínimo, desmistificado e posto a nu por Perry Anderson (1995), em seu artigo Balanço do Neoliberalismo. A atuação do Estado é mínima em relação aos gastos públicos-sociais e máxima em subsidiar e garantir a infraestrutura para as renovações e reestruturações financeiras, políticas, econômicas e ideoculturais da produção e mercado capitalista.

Portanto, a nossa primeira e principal tarefa, ainda não consumada, é desvelar e denunciar os renovados métodos e processos criados pelas personas que 
representam e encarnam os interesses e necessidades do capital para ludibriar as mentes, os corpos e os sentimentos dos trabalhadores, subsumindo o mundo do trabalho ao capital, pois é preciso romper com a alienação que alimenta a despolitização e subserviência dos trabalhadores, fortalecendo as formas de luta e resistência do mundo do trabalho, munindo-o e instrumentalizando-o com a tomada de consciência da conjuntura e situação histórico-produtiva que vive, a fim de que possa pensar em formas de mobilização e organização verdadeiramente eficazes e efetivas para a retomada do controle do social pelo e para o social.

Finalizando, resgatamos Gramsci (2004), pois acreditamos que suas ponderações acerca das condições para a emancipação dos trabalhadores e do mundo do trabalho ainda ecoam com atualidade e força incontestáveis. A emancipação dos trabalhadores pode encontrar sua força germinal através do trabalho como princípio educativo, pela apropriação por estes da contextualização histórico-social do significado humano e humanizador potencializado pelas forças produtivas materializadas nos instrumentos de trabalho, no conhecimento científico-tecnológico desenvolvido pela humanidade - daí a importância da apropriação, pelos trabalhadores, dos conteúdos socioculturais (conhecimento científico) - que tem a virtualidade de libertar o homem de toda forma de alienação, opressão e exploração.

\section{REFERÊNCIAS}

1,99 Um supermercado que vende palavras. Direção e roteiro: Marcelo Masagão. Brasil: Califórina filmes, 2003. 1 DVD (72 min.): DVD, Ntsc, son., color.

ALTHUSSER, Louis. Ideologia e Aparelhos Ideológicos do Estado. Lisboa, Editorial Presença, s/d.

ALVES, Giovanni. "Toyotismo como Ideologia Orgânica da Produção Capitalista". In: Dimensões da Globalização - 0 capital e suas contradições. Londrina: Praxis, 2001. 
ALVES, Giovanni. O novo (e precário) mundo do trabalho. Boitempo: São Paulo, 2000.

ANDERSON, Perry. Balanço do neoliberalismo. In: SADER, Emir; GENTILI, Pablo. (Orgs.) Pós-neoliberalismo: as políticas sociais e o Estado democrático. Rio de Janeiro: Paz e Terra, 1995.

DURKHEIM, Émile. Educação e Sociologia. Lisboa: Edições 70, s/d.

GARCIA, Joana. O Negócio do Social. Rio de Janeiro: Jorge Zahar, 2004.

GRAMSCI, Antonio. "Americanismo e fordismo". In: Obras escolhidas. São Paulo: Martins Fontes, 1978.

INSTITUTO ETHOS. Indicadores Ethos 2011. Disponível em <http://www.ethos.org.br>. Acesso em: 28 jul. 2011.

KOSIC, Karel. Dialética do Concreto. Rio de Janeiro: Paz e Terra, 1995.

LUKÁCS, George. As Teses de Blum (Extrato) - A Ditadura Democrática.

MARX, Karl; ENGELS, F. Obras Escolhidas. Tomo I. Lisboa: Edições Avante; Moscovo: Edições Progresso, 1982.

MÉSZÁROS, István. Produção Destrutiva e Estado Capitalista. 2. ed. Rev. e ampliada. São Paulo: Ensaio, 1996. (Cadernos Ensaio. Pequeno formato; v. 5).

MORAES, Reginaldo Carmello Corrêa de. As Incomparáveis virtudes do mercado políticas sociais e padrões de atuação do Estado nos marcos do Neoliberalismo. In, KRAWCZYK, Nora; CAMPOS, Maria Malta; HADDAD, Sérgio. (Orgs) O Cenário Educacional Latino-Americano no limiar do século XXI: reformas em debate. Campinas, SP: Autores Associados, 2000. (Coleção Educação Contemporânea) 
MOURA, Gustavo Alberto. "Sujeito ou Recurso Humano: Qual o lugar do trabalhador no processo e produção capitalista?" In: ARRAES NETO, Eneas (et.al.). Mundo do Trabalho - Debates Contemporâneos. Fortaleza: Editora UFC, 2004.

NAPOLEONI, Cláudio. Lições sobre o capítulo VI (Inédito) de Marx. Trad. Carlos Nelson Coutinho. São Paulo: Livraria Editora Ciências Humanas, 1981.

NOSELLA, Paolo. A escola de Gramsci. 3 ed. rev. e atual. São Paulo: Cortez, 2004.

Quanto vale ou é por quilo? Dirigido por Sérgio Bianchi. Brasil: RioFilmes, 2005. 1 DVD (104 min.): DVD, Ntsc, son., color.

ROSEMBERG, Fúlvia. Uma introdução ao estudo das organizações multilaterais no campo educacional. In, KRAWCZYK, Nora; CAMPOS, Maria Malta; HADDAD, Sérgio. (Orgs) $O$ Cenário Educacional Latino-Americano no limiar do século XXI: reformas em debate. Campinas, SP: Autores Associados, 2000. (Coleção Educação Contemporânea)

SALMON; Anne; CATTANI, Antonio David. Responsabilidade social empresarial. In: CATTANI, A. D. et al.(Orgs.). Dicionário internacional da outra economia. São Paulo: Almedina Brasil, 2009.

TEIXEIRA, Francisco José Soares. Pensando com Marx - Uma Leitura CríticoComentada de O Capital. São Paulo: Ensaio, 1995.

THE CORPORATION. Dirigido por Mark Achbar e Jennifer Abbott. Canadá: Zeitgeist films, 2003. 1 DVD (145 min.): DVD, Ntsc, son., color. Legendado. Port.

TONET, Ivo. "Marx e a política: Prefácio ao Glosas críticas... de Marx". In: Praxis. no 5. Belo Horizonte: Outubro-Dezembro, 1995. 
WANDERLEY, Luis Eduardo. Espaço Público e Educação. In, KRAWCZYK, Nora; CAMPOS, Maria Malta; HADDAD, Sérgio. (Orgs) O Cenário Educacional LatinoAmericano no limiar do século XXI: reformas em debate. Campinas, SP: Autores Associados, 2000. (Coleção Educação Contemporânea).

WEBER, Max. A Ética Protestante e o Espírito do Capitalismo. 4 ed. São Paulo: Livraria Pioneira Editora, 1985.

${ }^{1}$ E-mail: iaeldeo@gmail.com. Mestre em Ciências Sociais. Professora Assistente da Universidade Federal do Piauí. Departamento de Educação.

${ }^{2}$ E-mail: rra2@cin.ufpe.br. Doutorando em Ciência da Computação. Pesquisador da UFPE.

${ }^{3}$ E-mail: cleverson.nobrega@gmail.com. Mestre em Administração. Professor Assistente da Universidade Federal do Piauí. Departamento de Administração.

${ }^{4}$ Ver o documentário The Corporation.

5 Nessa direção, são interessantes dois documentários: THE CORPORATION e 1,99 - Um Supermercado que Vende Palavras.

${ }^{6}$ Ver o filme Quanto Vale ou é Por Quilo? Cena em que se ensina como confeccionar os projetos sociais de modo que sejam aprovados e garantam a captação de recursos - privado (venda de produtos e serviços) e público (fundo social).

RECEBIDO EM: 05.06.2012

APROVADO EM: 29.06.2012 